\title{
Sharing Resources: Benefits Of University Partnerships To Improve Teaching, Learning And Research
}

Ann Hilliard, Ph.D., Bowie State University, USA

\begin{abstract}
Today, many higher educational institutions are forward thinking about promoting strategic initiatives by establishing partnerships with other universities nationally and internationally. Being financial and academically savvy, universities are reaching out to meet the demands of public interests in different types of college programs and improving management processes at the university (Kruss, 2005). When universities share their human and non-human services and resources with a partner university, these universities could create effective ways to leverage more of their resources economically. The researcher will discuss the overall benefits of university partnering with another university, partnership processes, and effective communication and goal settings as partners, effective planning, international partnership benefits, and collaboration in project research, the importance of innovation and technology and evaluation of partnership objectives. University partnerships could improve many aspects of universities including, but not limited to, academic course offerings, economic status with gained support, social cross-culture advantage, political interest and support and create an environment that improves the quality of teaching, learning and research using technology.
\end{abstract}

Keywords: Educational Partnerships; University Partnerships; Educational Resource Sharing

\section{INTRODUCTION}

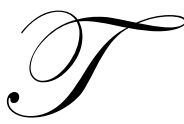

here are many benefits for universities to partner with another university or sharing their community resources. Partnerships create a culture of collaboration and innovations. University partnering with other universities can create a framework for improved teaching, learning, research, program development, leadership and services and improve the quality of academic programs. The new and improved knowledge learned through university collaboration can contribute to higher performance of faculty and students. Partnerships could cause each university to target improved ways of conducting professional development activities for faculty, students and staff to improve teaching, learning and research in broader communities. The use of technology could be enhanced through university partnerships through innovative research and development.

In the United States, university partnerships are increasing. Many universities are conducting more scientific research with the help of new and improved technologies. There are many universities that are gaining funding through their partnership relationship with other universities. Research-based universities are emerging with rich sources of innovative technology which are making these universities attractive to other universities that are seeking partnership relationships. Universities today are doing some traditional teaching and research, but for the past ten years many universities have become more innovative by conducting research for other universities to develop. Some forward thinking universities have gained access to licensing patents because of the quality of their research projects. Partnerships with universities can pave the way for other universities and companies to find and use new technologies to improve the physical infrastructure of university partnerships. Talented faculty members and their students are contributing to solving educational and industry problems in their area of expertise. Students at various universities are hired to work on specific projects and this helps to create a pool of future applicants for different industries. Many universities are willing to share their expertise of research so others may benefit from 
what works best to enhance a program or solve a problem. University partnerships are continuing to grow and that is great for academia and industry (Grobe, Curnam \& Melcoir, 1993).

\section{VALUES AND BENEFITS OF A PARTNERSHIP}

Universities partner with another university that could help to collaboratively address common academic and non-academic concerns or problems within the university and the community. The new governance between or among universities encourages the creation of innovative partnerships. With an engaging partnership with other universities, the benefits can be expansive in relationship to effective communication, faculty and student involvement, utilizing the community as a classroom, sharing research resources and experiences, funding sources, using new and improved technology, and using best practices for time investment in valuable research projects. Additionally, the value of university partnerships could expand needed educational services to broader communities to create a culture to help students and their parents, as adult learners too, to meet their academic potential. University partnerships could engage collaboratively in educational research in solving problems for educators, families and the community. With the diversity of experiences, university partnerships could provide faculty with more advanced and needed professional development to improve teaching and learning. Because of economical concerns today, university partnerships could help each other to make the best use of available resources in a creative and innovative manner (MacDonald \& Chrisp, 2005). These are ways that partnerships can enhance each other:

1. Encourage the creation of innovative partnerships to improve instructional delivery services to diverse groups of candidates or individuals

2. Use the whole concept of partnership to bring into being new and improved educational programs

3. Expand opportunities for faculty members to engage in collaborative research project activities

By working together, university partnerships could develop better models for instruction, management, and research. In the same community, there could be less duplication of efforts for humans to perform and the overuse of financial resources in order to carry out the vision and mission of the institutions or universities. Using the university partnership model when the economy is still in question, the relationship with partners could help educational leaders and stakeholders to have a greater commitment to educational access, equity and excellence (Rosen, 2002). There will be a continued need to establish and sustain appropriate resources for educational research and evaluation between or among partnerships in an integrated manner. University partnerships can serve as key players in keeping in focus relevant research development for the advancement and quality of education at the university nationally and internationally. By working together for success, university partners should participate in and have relevant knowledge about the partnership process.

\section{PARTNERSHIP PROCESS}

There are six major steps in the partnership process model as follows to ensure that there is a workable solution for the partnership relationship to have a chance for success.

1. Process of engagement is a major part of the model for stakeholders to follow in the process for sustainability of intervention of the partnership relationship strategically. Each stakeholder should listen, think, share and work collaboratively to communicate with clarity the intended vision, mission, core values, goals and objective based on the joint needs of the partnership. All actions must be viewed in a partnership thinking capacity. Stakeholders must be academically, socially and culturally sensitive to the needs of all partner universities

2. Cultural awareness is crucial too, because if there is not an awareness of culture differences this could create a concern in the process. Each participating university in the partnership needs to know in advance about the culture and history of the partner universities in order to have a clearer understanding of their beliefs, values, languages, practices, accomplishments and lingering concerns throughout the years. The lead or hosting university should remain very sensitive to building a positive working relationship with the partners in an effective manner. 
3. Intended collaboration helps each partner university to continue to think and act in a collaborative manner. Again, each university should try to keep an open mind and continue to learn about the partners' needs and interests. Avoid dominating the communication of activities agreed upon by the partners. Acquire knowledge of the partners' expertise, abilities and interests for future planning of joint events, activities and projects.

4. Building leadership capacity is essential because many individuals in the university partnership relationship have had many years of experiences and could help to produce or coordinate excellent projects to improve the quality of services at each university. For example, some individuals with the university partnership have successfully written and received grant funding and such talent in an organization would be an asset to all. The board of director or council and others could lead the way in discovering the key talents and leadership abilities of participating faculty and staff from various universities. The specific goals of each university may differ, but there would be some common ground for the universities to work together in a collaborative manner in order to get the best from the variety of resources that exist in each university.

5. University partnership's plan must always seek most effective ways to work with the host partners from the host region or country. The collaboration of the partners and leaders should clearly articulate the process for the partnership and the expected outcomes based on their strategic plan together. All stakeholders should be fully aware of the collaborative partnership plan. Effective communication of the plan for the partnership should be precise, concise and realistic. Sometimes, however, plans do not always work well as planned. Therefore, the plan should offer levels of sustainability of interventions to help to decrease possible occurring problems during the partnership relationship among the universities. There should be a stated duration of time for the partnership relationship through the strategic plan's action area (Iannuzzi, 1998). In order to have more clarity for the partnership process, typical universities partnership conceptual model is being communicated and illustrated in the next figure.

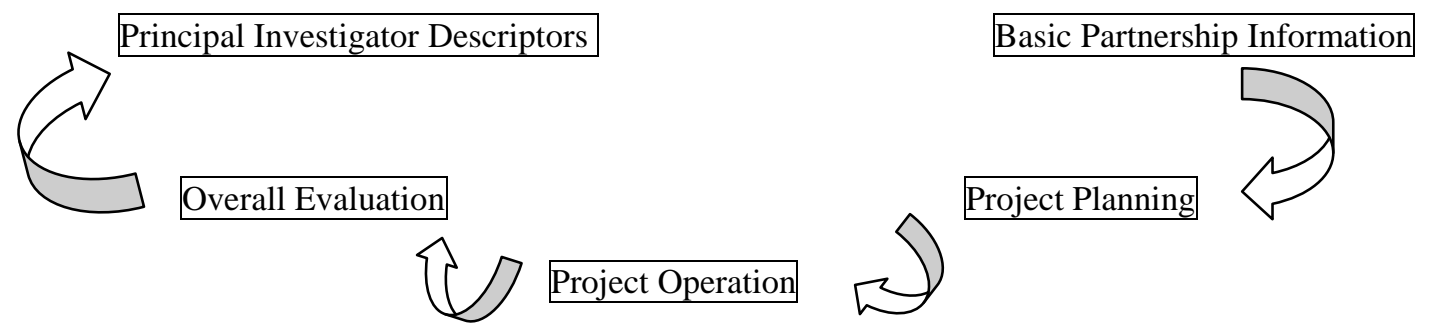

Figure 1: Universities Collaborative Partnership Conceptual Model

Source: Department of Education, 2003

The figure above depicts the conceptual model of a collaborative partnership framework for partnership universities. The basic partnership information helps to communicate clarity about the universities. Collaboratively, the stakeholders are able to conduct effective project planning activities for each university involved in the partnership. How the project will operate among the university partnerships is crucial to the success of the relationship. In order to know if partnerships are moving in the intended direction, it is importance to give an overall evaluation of the partnership mid-semester of each semester during the year. The frequency of evaluation allows all partners to see if there is a need to modify or revise the goals or objectives or to see other areas that may need revising in the strategic action plan. The principal investigator should serve as the overseer who works closely with the stakeholders and individuals who are responsible for implementing the strategic plan's actions in order to executive the set objectives to be accomplished. All responsible stakeholders for the university partnerships must have and maintain effective communication in order for the relationship to be successful.

\section{EFFECTIVE COMMUNICATION AND GOAL SETTING AS PARTNERS}

Effective communication is an essential key for partnership universities to work together. From the start of the relationship, lots of formal meetings are encouraged to look at each university's strengths, weaknesses, 
opportunities and threats in their collaborative strategic plan for organizational improvement. These areas should be reviewed so that each university has honest discussions why they need to bring together their human and no-human resources. During these early meetings, the goals, expectations and outcomes should be brought forth for discussion clearly among all stakeholders. However, the most productive partnerships between university partnerships take shape when the stakeholders find the right balance between their core educational development goals, organizational values, priorities, technical and educational competencies (Mohr \& Spekman, 1994). For example, some goals for university partnerships could be stated as follows:

1. Plan, organize and implement collaboratively a management system that could reduce duplications of financial and human resources

2. Develop collaboratively a strategic plan of intervention to ensure that all partnership universities can increase their academic performance in a positive manner

3. Use data to justify all planning for instructional and managerial improvement

4. Share qualitative and quantitative research and best practices to enhance teaching, learning and research and improve student achievement at all levels

Effective communication is essential, because members of the collaborative leadership team should be totally clear by communicating why the university partnership would be an advantage. These areas of consideration should be stated before the agenda meeting ends again for clarity: measurable objectives, ways of communicating, appropriate decision making, roles and responsibilities and accountability, skills and knowledge of participants, expectations of managers and leaders, ways of performing tasks based on guidelines/timelines, and outcomes in compliance with state and national standards. After key goal settings have been established, it is now time to practice effective planning with university partners (Sandmann, Baker-Clark, 2007).

\section{EFFECTIVE PLANNING IS A MUST FOR PARTNERSHIPS}

Some university partnerships are not successful, because the partners failed to plan jointly together to accomplish identified goals and objectives. The strategic plan should address the priority needs of the partners in a collaborative manner. Partners sometimes do not plan well for the needed time to carryout goals and objectives for the partnership relationship to grow in a positive manner. Some partners are not prepared for the partnership relationship and they feel over taxed to carry out their roles and responsibilities. Preparation for a partnership could be improved if partners could plan, organize, implement, monitor and evaluate the entire process through a joint effort. University partnerships that are successful generally function in a similar manner in reference to governance and accountability for all (Sandman \& Waldschimdt, 2006).

Effective planning framework is very important in order to lead the university partnerships in the most productive direction of success. These are some suggestions for partners to consider in the plan jointly.

1. State the purpose of the partnership in clearly defined language

2. Focus on improvements to the provision of services and the well-being of university partnership communities.

3. Make sure that the participants understand the rationale and are committed to it.

4. Identify the role and respect the roles of partner organizations

5. State the statutory role of what partners are expected to deliver.

6. Create and maintain a culture of trust and openness to be nurtured within the partnership.

7. State the expectations of this joint commitment for the partnership to succeed.

8. Take into account the views and interest of the partnership participants.

9. Create a written policy and procedures for new partners to enter and an exit strategy when applicable from the partnership.

10. Assess formally from reviews how well the partnership is fulfilling its purpose, and decide on action to improve if and when applicable.

11. Make the review assessment public for stakeholders to see in a clear and precise language.

12. Show in writing the process of performance management expectations.

13. Make sure that targets are set for delivery in measurable terms 
14. Monitor monthly or every quarter the performance of the university partnership for relationship improvement and quality of services.

15. Set up a collaborative way of evaluating university partnerships formally at the end of each semester (Audit Commission, 1998).

\section{INTERNATIONAL PARTNERSHIPS BENEFITS}

Looking at the expansion of global connections, many universities are seeking the integration of international and multicultural perspectives and experiences in teaching, learning and research. Engaging in this opportunity internationally, universities and colleges could increase faculty, staff and students exposure to new ways of learning, discovery and enrich the mission of their own higher education environment (Knight, J. 1994). International partnership initiatives can provide faculty and students with the opportunity to participate in collaborative activities in multicultural settings which could add to participants' knowledge and skills. Faculty and students could enrich their own experiences academically, socially and culturally by having an international partnership. The partnership universities could:

1. Participate in promising international research and scholarship, particularly that which incorporates and expands student scholarship opportunities.

2. Help in the development of innovative curricula that strengthens the preparation of faculty and student scholars for an increasingly global future.

3. Expose underserved students to study in programs at universities abroad

4. Increase international and multicultural respect and understanding of previously underserved constituencies in the university's communities.

5. Expand recruitment and/or meaningful engagement of international students in scholarly studies and research

6. Serve as good will ambassadors representing the U.S.A. in other parts of the world

Because of the availability of technology, university partnerships can be near or far way in international settings that could improve learning experiences for faculty and students in various disciplines. Having access to current technology, faculty and students can continue to build viable relationships with national and international universities in joint partnerships on special projects on land, at sea and space. This relationship could foster new and improved ways of establishing high quality services and products as an outcome to the public at large globally (Roberts \& O’Connor, 2008).

\section{COLLABORATION IN PROJECT RESEARCH}

When universities collaborate, faculty and students may benefit from this relationship. For example, faculty members could be the key to influence groups to get behind and push for new initiatives to improve instruction, teaching, learning and research for students. Faculty members could be major players to work on strategic planning for student housing development, transportation and creating new curriculum and courses for student advancement. Several students maybe involved in service research projects that could be extended to be in collaboration with student at other universities. These research projects could be community-driven. For example, some community projects or activities could be related to home improvement tasks, assistance given to special needs individuals within the community, and serve as team tutors to elementary and secondary school students. Many universities are engaging in research for improving teaching and learning which could link to energy resources and exploration projects plus ways to decease health issues globally. Faculty members could participate in joint research projects too, in the area of data collection, analysis and to seek grant support for the universities to make a difference in broader communities (Martin, 2003).

\section{IMPORTANCE OF INNOVATION AND TECHNOLOGY}

Technology is here to stay! Technology is used in the broader sense for instruction and management efforts at universities and other organizations. Working together in a partnership relationship at universities, the whole aspect of learning can be presented in many different venues to meet the needs of faculty, staff and students. 
Technology can help to articulate the vision, mission, goals, objective and strategic action plan for partnership universities. University partnerships that embrace the essence of technology as a managerial and instructional tool have generally had better records of success compared to non-partnership universities (Lynch, 2000).

Using technology today is a way for partners to stay in touch with each other in real-time locally or from afar. Some university partners can serve as mentors to help their partners to become more proficient in using new and improved technologies. Meaningful recommendations in effective technology use as a support tool in the instructional and managerial aspect of the university is in common use today. Technology is being used in innovative ways to enhance professional development, recruitment and marketing efforts, university registration, complete and submit assignments to faculty, to evaluate federal grant programs and management of budgetary matters just to name a few (McKenzie,1999).

Technology use in the university and other industries has been credited as being one of the key factors in increasing productivity and time saving measures in many organizations. It is believed that the use of technology as an instructional and managerial tool could do more to improve educational opportunities and quality than any recent innovation. Some universities find that investing in useful and appropriate technology is worthwhile. The use of technology in partnership relationships is not as expensive as one may think. Smart planning and selecting technology applications have proven to be a wise investment economically in joint partnerships. According to many researchers in summary, the innovation and appropriate use of technology can and does increase education productivity in real-time within an organization (Byrom \& Bingham, 2001).

\section{EVALUATION OF PARTNERSHIP OBJECTIVES}

In order to learn if the university partnership is effective, it is necessary to evaluate the intended objectives of the partnership. The evaluation of the partnership objective is designed to include measurable aspects of assessing the quality of performance of the university partnership. The evaluation should include the strengths, weaknesses; opportunities and treats (SWOT) of the university partnerships. All aspects of the evaluation process should be in measurable terms. The what, who, whom, when, where, why and how should help to address if the objectives are met or being met up-to-date. The information given should be clear, precise and in measurable terms regarding the evaluation format. For example on a likert scale from 1 to 5 with five being the highest possible point, the evaluation of the questions below could be used for the partnership relationship. In many areas, the scale level may address frequency, quality and satisfaction of the partnership relationship between or among the universities.

1. To what extent did the university partnership meet its objectives?

2. To what extent were the needs of faculty and students met?

3. To what extent were the questions refined enough to meet the standards for each partner individually and as a collaborative group?

4. To what extent were there unanticipated impacts on the university partnerships if applicable?

5. To what extent were there illustrations of confidentially among university partnerships as a team?

6. To what extent was information of analysis shared with faculty, staff and students regarding the university partnership?

The evaluation of the effectiveness of the university partnership could be done in many different ways. However, a common or simple way of evaluating the relationship's effectiveness could be done on an ordinal level using a likert scale as stated before and could be analyzed every month or four times a year. The primary stakeholders working with an independent council could prepare the questions of concern for evaluation and suggest ways to use the results as baseline data for future relationships. In order to keep an ongoing accountability of how well the partnership is working, it may be wise too, to incorporate faculty/student/staff to participate in interviews, open-ended questionnaires or surveys from written professional development training experiences among partners, and conduct informal observations. The evaluation results should be made available to all partnership stakeholders timely. The council assessor administering the university partnership evaluation information should seek feedback in a manner that shows professionalism. The results of the analyzed data collected could be available for all stakeholders to review and use for future program planning for improvement by the participating university partners (Lowndes \& Skelcher, 1998). 


\section{CONCLUSION}

In summary, university partnerships are alive and well. There remains a strong need for continuous collaboration between or among university partnerships. Out of economic necessity, more universities are partnering with communities resource agencies and other universities to expand, enhance and sustain their college programs in teaching, learning, professional development and research. Managers, faculty and stakeholders need to stay mindful of the critical need to establish goals and objectives together for innovative programs to ensure that their services remain of high quality to serve students not only locally but internationally. There must be reminders to all that quality college programs and services must continue to be a number one priority in order to gain the value and benefits of university partnerships for faculty, staff and students. Because of the world's need for competitive readiness among its citizens, university partnerships must keep a key eye on what will create and sustain a generation of highly qualified/certified and productive faculty, staff and students and eventually a highly productive workforce that can compete effectively in global societies.

\section{AUTHOR INFORMATION}

Ann Toler Hilliard, Ph.D., is assistant professor, teaches in the Department of Educational Studies and Leadership at Bowie State University, U.S.A. The author has taught classes in human resources, educational policy, educational planning and evaluation, and group dynamics. She is interested in research related to finding ways to improve the dissertation experience for doctorate candidates, data-driven decision making at the university, best practices for decreasing the number of dropouts in graduate programs in colleges/universities. Dr. Hilliard has her Ed.D. from George Washington University, M.S. from Johns Hopkins University, M.A.T. from Trinity University, and B.S. from Elizabeth City State University. E-mail: draph1@ juno.com

\section{REFERENCES}

1. Audit Commission (1998) A fruitful partnership: effective partnership working, London: Audit Commission

2. Byrom, E., and Bingham, M. (2001). Factors influencing the effective use of technology in teaching and learning. Retrieved March 18, 2004, from http://www.seirtec.org/publications/lessons.pdf .

3. Department for Education and Skills (2003) Collaboration: learning partnerships and stakeholders, a guide, London: HMSO.

4. Grobe, T., Curnam, S. P., \& Melchoir, A. (1993, October). Synthesis of existing knowledge and practice in the field of educational partnerships. Washington, D C: Office of Educational Research and Improvement. ERIC Document Reproduction Service No. ED362994

5. Iannuzzi, P. (1998) "Faculty Development and Information Literacy: Establishing Campus Partnerships" Reference Services Review, 26, no. 3-4, 97-102+

6. Knight, W. J, (2003). William J. Knight Foundation, Inc.

7. Kruss, g. (2005) "Financial or Intellectual Imperatives: Working Partnerships in Higher Education, Industry, and Innovation." HSRC Press, 2005.

8. Lowndes, V. \& Skelcher, C. (1998). The dynamics of multi-organization partnerships: An analysis of changing modes of governance. Public Administration, 76, 313-333.

9. Lynch, J. (2000, September 7-10). Teacher access to computer-based information and communication technology: Resources are not the whole answer. Retrieved March 29, 2004.

10. Macdonald, S. \& Chrisp, T. (2005). Acknowledging the purpose of partnership. Journal of Business Ethics, 59, 307-317.

11. Martin, L., Myers S, Nelson, J., Phillips. W. \& Smith, H.P. (2003). Review of the Orange County Central Receiving Center, University of Central Florida.

12. McKenzie, J. (1999, May). Strategic deployment of hardware to maximize readiness, staff use and student achievement. The Educational Technology Journal. 8 (8). Retrieved March 18, 2004.

13. Mohr, J. \& Spekman, R. (1994). Characteristics of partnership success: Partnership attributes, communication behavior, and conflict resolution techniques. Strategic Management Journal, 15, 135-152. 
14. Roberts, J. and O'Connor, P. (2008) "Inter-Agency Service Collaboration in the NPO Sector-Report Overview.", 15th International conference on Multi-Organizational Partnerships, Alliances and Networks. MOPAN 2008, Boston, MA, June 25-27, 2008.

15. Rosan, R. (2002). The Key Role of Universities in our Nation's Economic Growth and Revitalization: the Innovation Journal: the Public Sector Innovation Journal, Vol. 10 (2), article 20.

16. Sandmann, L. \& Baker-Clark M. (2007). Characteristics and Principals of University Community Partnerships: A Delphi Study.

17. Sandmann L, \& Waldschmidt, D. (2006). Faculty Persistence in Outreach, University of Nebraska, Lincoln. 